\title{
Large Organellar Changes Occur during Mild Heat Shock in Yeast
}

Katharina Keuenhof ${ }^{1}$, Lisa Larsson Berglund ${ }^{1,2}$, Sandra Malmgren Hill ${ }^{3,4}$, Kara L Schneider ${ }^{2}$, Per O Widlund ${ }^{2}$, Thomas Nyström² ${ }^{2}$ Johanna L Höög ${ }^{1}$

${ }^{1}$ Department for Chemistry and Molecular Biology, University of Gothenburg, Sweden

${ }^{2}$ Department of Microbiology and Immunology, The Sahlgrenska Academy at the University of Gothenburg, Sweden

${ }^{3}$ Department of Psychiatry and Neurochemistry, Institute of Neuroscience and Physiology, The Sahlgrenska Academy at the University of Gothenburg, Sweden

${ }^{4}$ Department of Medical Genetics, Cambridge Institute for Medical Research, United Kingdom

Corresponding author: Johanna L Höög, johanna.hoog@gu.se

\section{Summary statement}

Exposure to mild heat shock leads to large quantifiable changes in the cellular ultrastructure of yeast, shows involvement of MVBs in the heat shock response and the apparition of novel structures. 


\section{Abstract (174/180 words)}

When the temperature is increased, the heat shock response is activated to protect the cellular environment. The transcriptomics and proteomics of this process are intensively studied, while information about how the cell responds structurally to heat stress is mostly lacking. Here, Saccharomyces cerevisiae were subjected to a mild continuous heat shock and intermittently cryo-immobilized for electron microscopy. Through measuring changes in all distinguishable organelle numbers, sizes, and morphologies in over 2400 electron micrographs a major restructuring of the cell's internal architecture during the progressive heat shock was revealed. The cell grew larger but most organelles within it expanded even more. Organelles responded to heat shock at different times, both in terms of size and number, and adaptations of certain organelles' morphology were observed. Multivesicular bodies grew to almost $170 \%$ in size, indicating a previously unknown involvement in the heat shock response. A previously undescribed electron translucent structure accumulated close to the plasma membrane during the entire time course. This all-encompassing approach provides a detailed chronological progression of organelle adaptation throughout the cellular stress response. 


\section{Introduction}

Increasing the temperature activates the cell's heat shock response. This is an ancient and evolutionarily conserved transcriptional program that results in reduced expression of genes involved in protein biosynthesis pathways and increased expression of genes encoding heat shock proteins (Verghese et al., 2012a). The heat shock response is also activated by other types of stressors, for example oxidative stress, exposure to heavy metals, fever, and protein conformational disorders (Morimoto and Westerheide, 2010).

Heat shock in budding yeast (Saccharomyces cerevisiae) is extensively used as a model to study neurodegenerative human diseases (Winderickx et al., 2008; Kaliszewska et al., 2015), where inclusion bodies of aggregated misfolded proteins accumulate at specific sites in the cytoplasm and nucleus (Takalo et al., 2013; Chung, Lee and Lee, 2018). Examples of such diseases are Alzheimer's, Huntington's, and Parkinson's (Tenreiro et al., 2013).

In eukaryotes, the heat shock transcription factor (HSF) is responsible for the induction of heat shock genes. It exists in its inactive form during non-stress conditions and is activated when there is an accumulation of destabilised, misfolded proteins in the cell. HSF binds DNA and initiates transcription (Morimoto, 1993). The heat shock-induced changes in transcription and translation ensure that the cell is capable of maintaining proteostasis and metabolism when experiencing temperature stress (Mühlhofer et al., 2019). While many of these molecular mechanisms of the cellular heat shock response have been widely studied, the wide-reaching structural and architectural effects of such a temperature change are often neglected because attention is focused on the system of interest, e.g. the transcriptome, proteome, and/or the behaviour of misfolded proteins (Shi, Mosser and Morimoto, 1998; Verghese et al., 2012b).

In this study, we investigated the structural adaptations that cells undergo when subjected to a mild $38^{\circ} \mathrm{C}$ heat shock. A heat shock that is comparable to that used when studying protein quality control as well as temperature sensitive mutants. Using electron microscopy of highpressure frozen cells, we obtained ultrastructural information on nearly every cellular organelle and substructure, without being limited by fluorescent labelling of a few candidate proteins such as those used in previous studies (Meaden et al., 1999; Lewandowska et al., 2006; Spokoini et al., 2012; Escusa-Toret, Vonk and Frydman, 2013; Meyers et al., 2016; Gao et al., 2017). To gain a nanometre-resolution map of cellular alterations prompted by heat shock that is as comprehensive as possible, a minimum of one hundred cells were imaged for each time point throughout a continuous $90 \mathrm{~min}$ exposure to $38^{\circ} \mathrm{C}$. The time course and subsequent imaging was performed in triplicates, yielding a total of 2143 images analysed for an overview that comes as close to a screen as possible using electron microscopy. The resulting temporal map of cellular restructuring reveals that heat shock induces major morphological changes to the cells' internal architecture and composition and that more organelles than anticipated are involved in this process. 


\section{Results}

\section{Heat shock has wide-reaching effects on cell structure}

We used electron microscopy to study the ultrastructural changes occurring in yeast during a mild heat shock over a time course of $90 \mathrm{~min}$ (fig. 1A). Samples of yeast cultures were collected at $30^{\circ} \mathrm{C}$ and after a $5,15,30,45$, or $90 \mathrm{~min}$ shift to $38^{\circ} \mathrm{C}$. These samples were cryo-immobilised using high-pressure freezing followed by freeze substitution for best possible morphological preservation (Moor, 1987; Perktold et al., 2007). Samples were then sectioned into $70 \mathrm{~nm}$ thin sections. At least 100 random images were collected at a magnification where the entire cell could be visualised in detail (9300x, pixel size $1.1 \mathrm{~nm})$. The whole experiment was repeated three times.

Observations of cells subjected to such temperature stress revealed unexpectedly large changes in cellular architecture (fig. 1B). Organelles, such as lipid droplets (LDs) seemed to increase both in numbers and size (fig. 1B, see 5 and $45 \mathrm{~min}$ ). Electron dense content, presumably protein aggregates, was observed in both the nucleus and mitochondria (fig. 1B, see 15, 30, 45, and $90 \mathrm{~min}$ ). Previously undescribed electron translucent clusters (ETC) appeared often in close proximity to the plasma membrane (fig. 1B, see 45 and $90 \mathrm{~min}$ ). However, the most prominent difference being an altered morphology of the vacuole. In heat treated cells, the vacuole appeared to change both in texture, electron density and size (fig. 1B, compare 0 and $30 \mathrm{~min}$; fig. S1). To further investigate these cellular adaptations, we progressed to outline all distinguishable organelles and quantify their number and area. 
bioRxiv preprint doi: https://doi.org/10.1101/2021.01.25.428102; this version posted January 26, 2021. The copyright holder for this preprint (which was not certified by peer review) is the author/funder, who has granted bioRxiv a license to display the preprint in perpetuity. It is made available under aCC-BY-NC-ND 4.0 International license.

A $3 x$

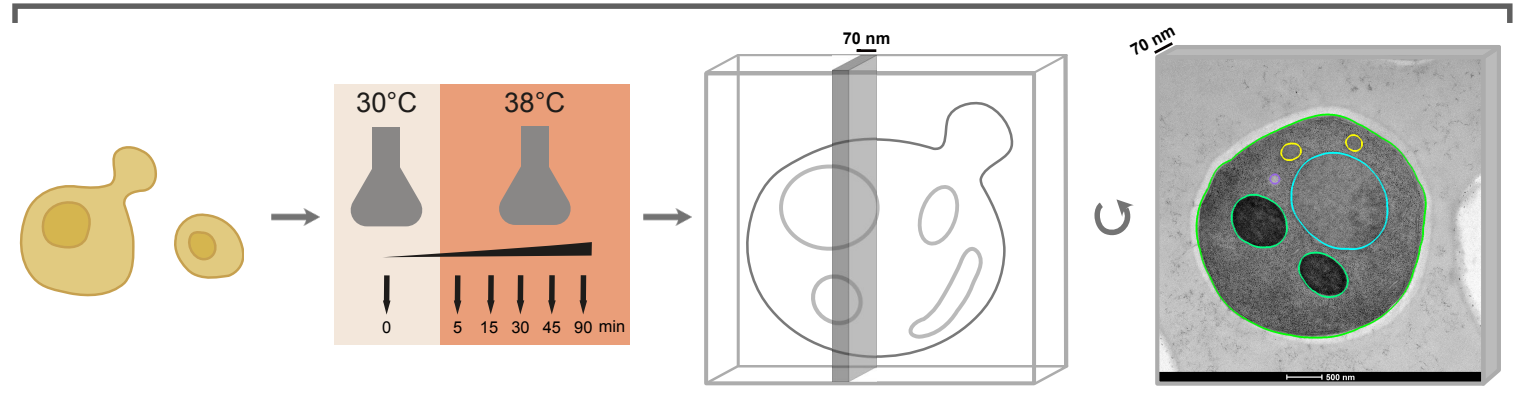

B
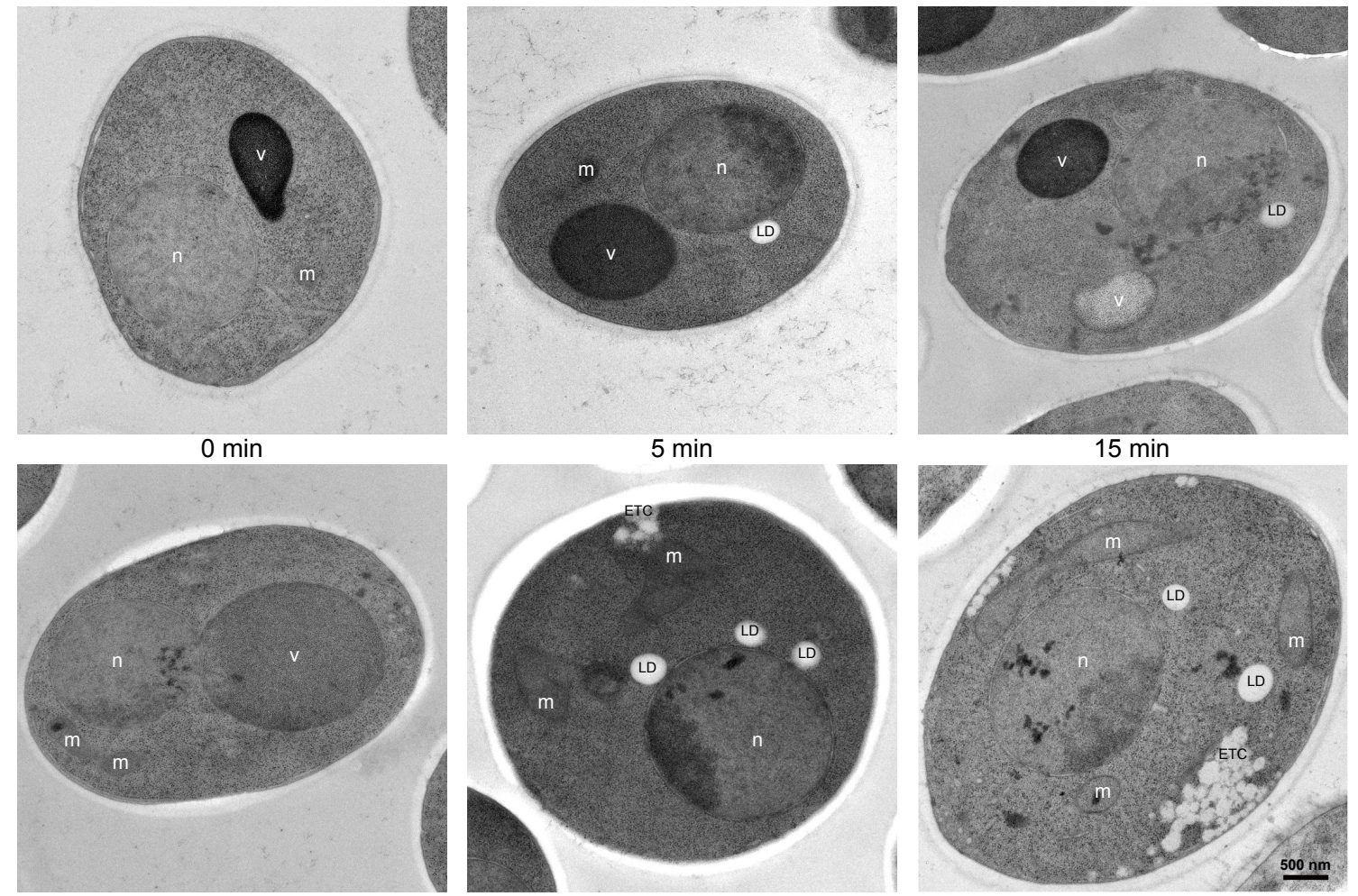

$45 \min$

$90 \min$

Figure 1. Revealing ultrastructural changes during a mild heat shock using a transmission electron microscopy screening method A) Cartoon of the experimental procedure: Cells were grown at $30^{\circ} \mathrm{C}$ and heat shocked at $38^{\circ} \mathrm{C}$ for $0,5,15,30,45$, and 90 minutes. Cells were then high-pressure frozen, freeze-substituted and sectioned to $70 \mathrm{~nm}$ for electron microscopy. Each heat shock experiment was done in triplicate and at least 100 images were collected of each sample, resulting in a total of 2143 images analysed. Size and morphology of all clearly visible organelles were quantified to reveal known and unknown effects of exposing yeast cells to heat shock. B) Example images show that large morphological changes and cellular reorganization occurred during heat shock. Further, a new phenotype that we call electron translucent clusters (ETC) appear during heat shock. Nucleus (n), vacuole $(\mathrm{v})$, mitochondrion $(\mathrm{m})$, lipid droplet (LD).

\section{Vacuoles and the cell as a whole increase in size throughout heat shock}

Outlining 2143 plasma membranes over the 6 different time points revealed that the average cell area increased by $19 \%$ over the 90 min heat shock (fig. 2A-B). A notable growth occurred between 15 and $30 \mathrm{~min}$, as the first three timepoints all differ significantly from the last three.

The vacuole often occupies the most amount of space in the cell, but during heat shock it grew even more compared to the cell volume ( $\mathrm{n}=2866$; fig. $2 \mathrm{C}$ ). Vacuoles increased in size, peaking after 45 min of heat shock at an area 69\% larger than their original size (fig. 2C). After this, they shrunk slightly but by 90 min still remained $48 \%$ larger than before heat shock. 
Since electron microscopy sections are too thin to contain a whole vacuole, and may not accurately represent the number of large organelles in the cell, we also investigated their change in terms of numbers and shape throughout stress using fluorescence microscopy. Cells expressing Vph1-GFP (fig. 2D), a subunit of the vacuolar ATPase $\mathrm{V}_{0}$ present in the vacuolar membrane (Hecht, O’Donnell and Brodsky, 2014) were used to this purpose. Whilst the number of vacuoles decreased by $41 \%$ over the course of 90 min (non-heat shocked $1.26 \pm$ $0.05 \mu \mathrm{m}^{2}, \mathrm{n}=614,90 \mathrm{~min}$ heat shock $2.49 \pm 0.18 \mu \mathrm{m}^{2}, \mathrm{n}=624$; fig. $2 \mathrm{E}$ ), at $45 \mathrm{~min}$ of heat shock they were 2.2 times as large as the control. After $90 \mathrm{~min}$ the vacuole was still twice as large as before heat shock (fig. 2F). This shows that vacuoles probably respond to heat shock by fusing and creating few large organelles rather than many smaller vacuoles. Further, a change to their internal morphology was also observed. 
bioRxiv preprint doi: https://doi.org/10.1101/2021.01.25.428102; this version posted January 26, 2021. The copyright holder for this preprint (which was not certified by peer review) is the author/funder, who has granted bioRxiv a license to display the preprint in perpetuity. It is made available under aCC-BY-NC-ND 4.0 International license.

A

No HS

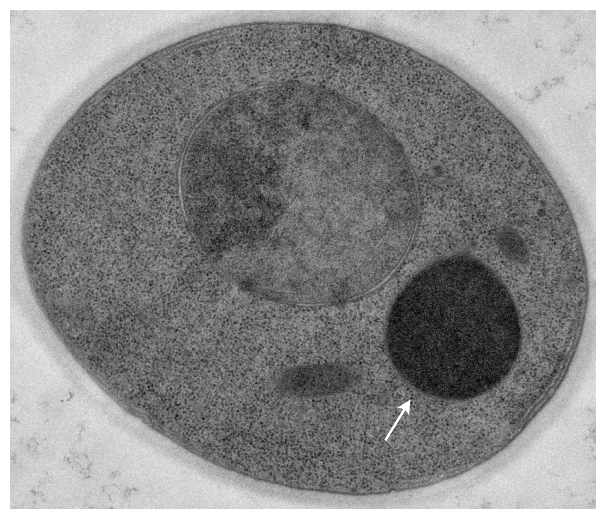

B

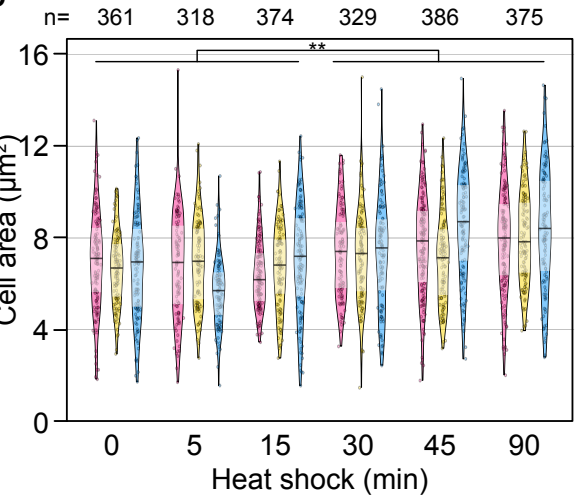

30 min HS

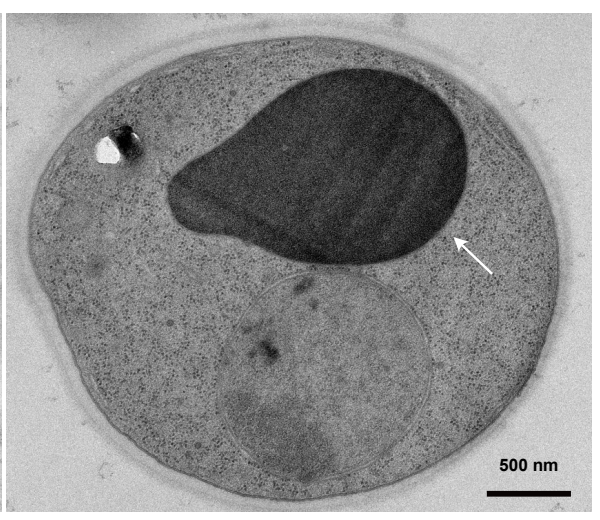

C

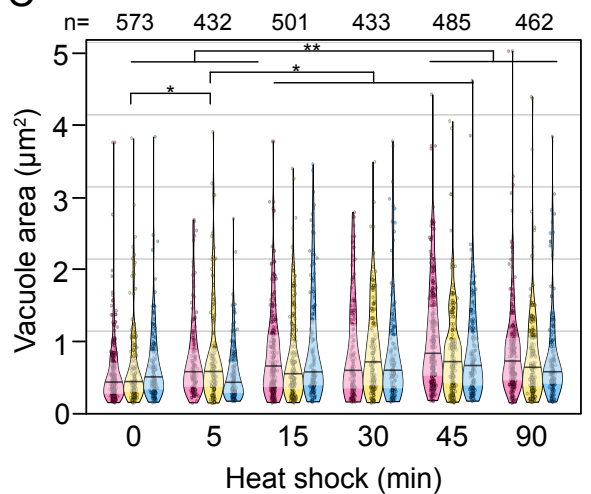

pink $=$ replicate 1, yellow $=$ replicate 2 , blue $=$ replicate 3

D

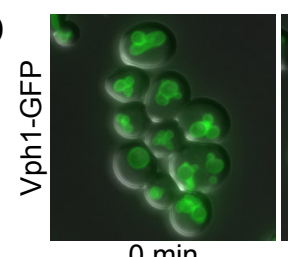

$0 \mathrm{~min}$

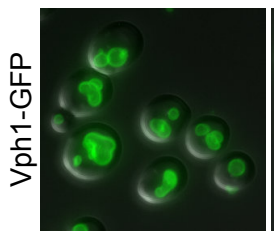

$30 \mathrm{~min}$

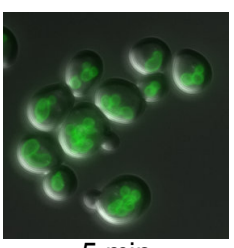

$5 \mathrm{~min}$

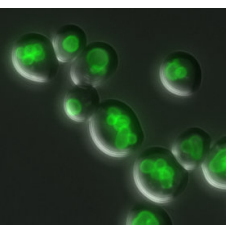

$45 \mathrm{~min}$

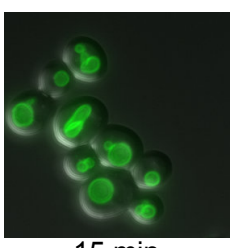

$15 \min$

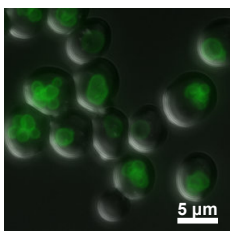

$90 \mathrm{~min}$
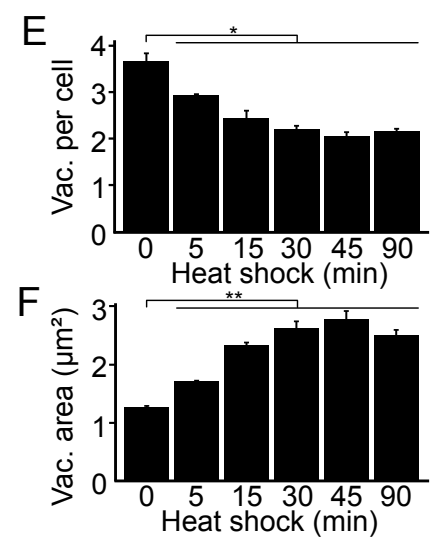

Figure 2. Cells and vacuoles increase in size A) Cells with vacuoles (arrow) before and after 30 min of heat shock. B) Cell area in electron micrographs of thin sections. On average, the cell size increases by $19 \%$ over the course of 90 minutes. The pink, yellow and blue shapes represent the three separate replicates. The width represents the number of measurements within a certain range of values, one point represents one measurement. Solid line is the median and inference bands are the interquartile ranges. C) Vacuoles in electron micrographs of thin sections. On average, the vacuole size increases by $48 \%$ over the course of 90 minutes. D) Cells expressing Vph1-GFP heat shocked at indicated time points. E) Quantification of vacuole number per cell from cells in A, n > 200 per replicate and time point. F) Quantification of vacuole size from cells in $A, n>200$ per replicate and time point. Bars show the mean of three replicates, error bars are the standard error of the mean. Significances: $\left({ }^{*}\right) p<0.05,\left({ }^{* *}\right) p \leq 0.01$.

\section{Vacuolar texture and electron density change in response to heat shock}

A striking variation in electron density of the vacuolar lumen was observed with electron microscopy. In logarithmically growing non-stressed yeast cells, vacuoles are often very 
electron dense. After heat shock, the vacuoles were oftentimes electron translucent and sometimes contained a grainy texture. Vacuoles were therefore classified into four major categories according to their appearance: dense, grainy, medium, and translucent (fig. 3A). The electron density of vacuoles fluctuated strongly throughout the time course in each experiment, showing lower electron densities when exposed to stress and a recovery to darkly stained vacuoles at 90 minutes (fig. 3B).

When comparing electron micrographs of dividing cells, daughter cells had either a higher or equal vacuolar electron density when compared to their mother (fig. 3C and 3D). A previous study showed that upon cell division in yeast, the daughter cell has a more acidic vacuole than its older mother cell (Hughes and Gottschling, 2012). We thus hypothesized that lower electron density in vacuoles could be due to a deacidification of that organelle. The effect of vacuolar $\mathrm{pH}$ on the electron density of the samples was investigated using cells from a vma2 $\triangle$ strain (fig. 3E). Vma2 is a subunit of the V1 domain of the vacuolar $\mathrm{H}^{+}$ATPase and its deletion causes an increased vacuolar $\mathrm{pH}$ compared to its usual $\mathrm{pH}$ of 5-6.5 ( $\mathrm{Li}$ and Kane, 2009). As opposed to wild type cells, almost all vacuoles in vma2 $\Delta$ cells displayed the electron translucent phenotype, demonstrating that increased $\mathrm{pH}$ leads to altered vacuolar staining (fig. 3E and 3F). To determine if vacuoles deacidify during heat shock we used the $\mathrm{pH}$ sensitive vacuolar probe BCECF-AM, which displays increased fluorescence at increased $\mathrm{pH}$ (Plant et al., 1999; Hughes and Gottschling, 2012). As a positive deacidification control, BCECF-AM staining also confirmed the expected elevated $\mathrm{pH}$ in the vma24 mutant (fig. $3 \mathrm{G}$ and $3 \mathrm{H}$ ). Vacuoles exposed to $45 \mathrm{~min}$ heat shock fluoresced brightly, compared to those of cells grown at $30^{\circ} \mathrm{C}$, confirming that heat shock causes elevated internal $\mathrm{pH}$ in vacuoles (fig. $3 \mathrm{G}$ and $3 \mathrm{H}$ ). Therefore, using our protocol, changes in vacuolar $\mathrm{pH}$ can be observed as altered electron density of the vacuolar lumen.

To summarise, vacuoles are affected by heat shock in several ways; a decrease in number, an increase in size and increased luminal $\mathrm{pH}$. 


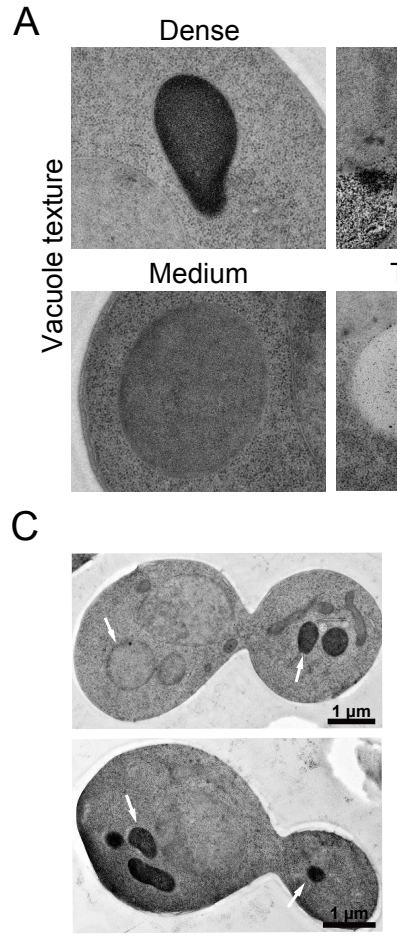

F

$\mathrm{H}$
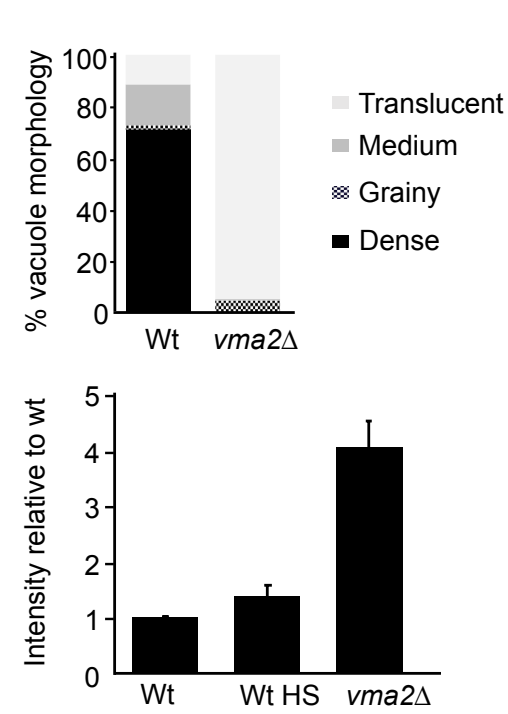

$\mathrm{D}$
B
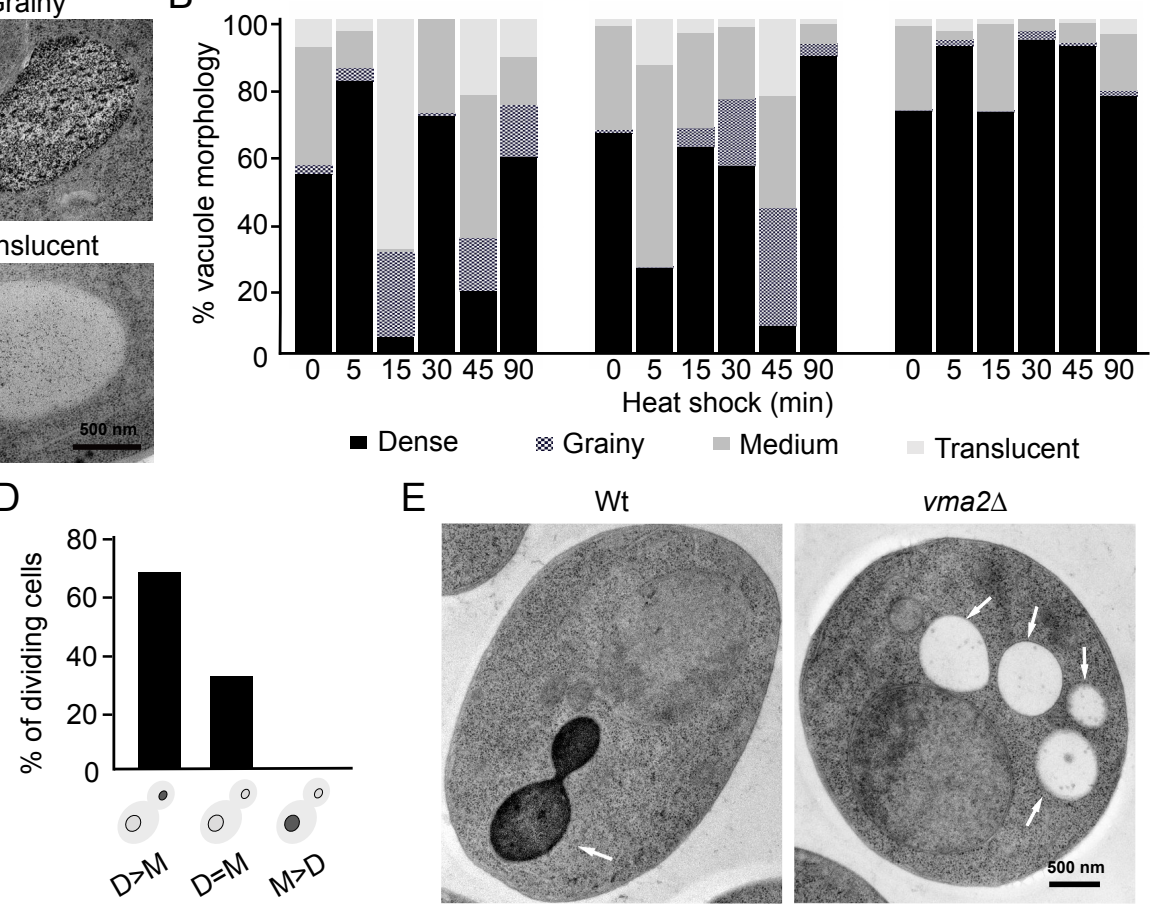

E
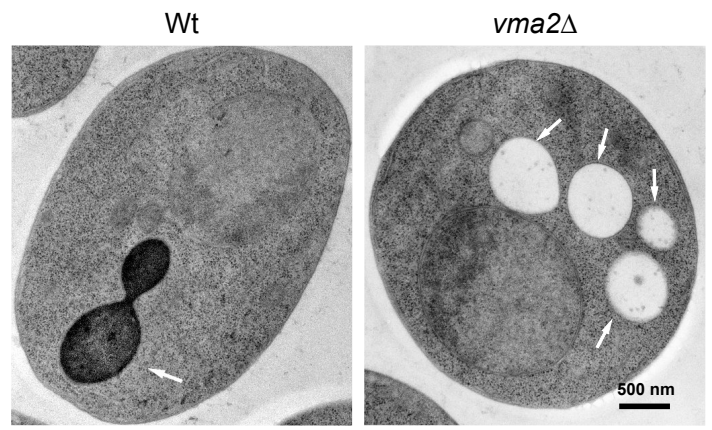

G

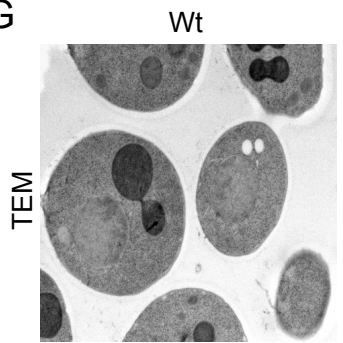

Wt HS
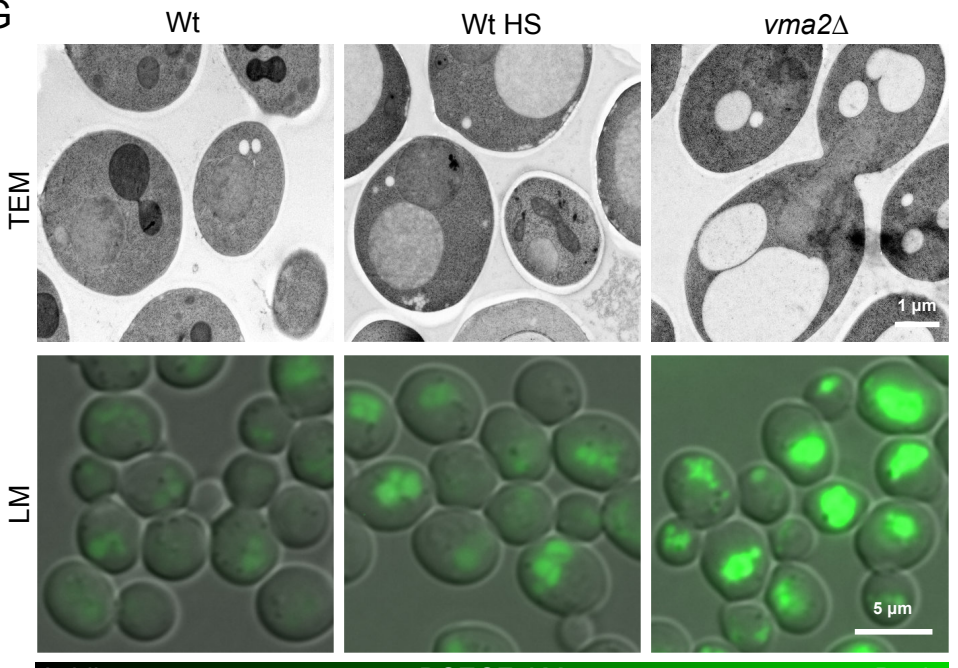

Figure 3. Heat shock affects vacuolar morphology and acidity A) Gallery of different vacuolar electron densities. B) Quantification of vacuolar electron density during heat shock. More than 100 vacuoles were analyzed from three independent experiments respectively. C) EM images of dividing wt cells grown at $30^{\circ} \mathrm{C}$. D) Quantification of electron density of vacuoles in mothers (M) and their daughters (D) during cell division, $n=53$ dividing cells. E) EM images of Wt and vma2 $\Delta$ grown at $30^{\circ} \mathrm{C}$. F) Quantification of vacuolar electron density of $\mathrm{E}, \mathrm{n}=181(\mathrm{Wt})$ and 274 (vma2 $\Delta$ ) vacuoles from a minimum of 100 cells. G) EM and fluorescence microscopy of indicated strains. HS is 45 min at $38^{\circ} \mathrm{C}$. The fluorescent pH-sensitive probe $\mathrm{BCECF}$ accumulates in yeast vacuoles and shows vacuolar $\mathrm{pH}$. The more fluorescence, the more basic vacuolar $\mathrm{pH}$. H) Quantification of vacuolar BCECF fluorescence mean intensity. More than 30 vacuoles were analyzed from three independent experiments respectively. Graph shows mean relative values to wt fluorescence mean intensity with error bars corresponding to standard deviation.

\section{Nucleus and mitochondria change in size and develop electron dense content throughout heat shock progression}

The nucleus was also affected by the increase in temperature (fig. 4A). Surprisingly, a significant shrinkage (11\% smaller than before heat shock) occurred $15 \mathrm{~min}$ after temperature shift (fig. 4B). The nucleus then recovered the same approximate size as before. Nuclear morphology was also altered and electron dense content (EDC, arrow in fig. 4A) became more 
prominent as heat shock progressed. The proportion of nuclei containing EDC increased rapidly with the onset of heat shock, coinciding with the decrease in size, but had decreased again slightly by $90 \mathrm{~min}$ (fig. 4C).

As one cell section may contain several mitochondria (fig. 4D), 2851 mitochondria were analysed (fig. 2E). Similar to the nucleus, mitochondria were only $75 \%$ of their size in untreated cells after 15 minutes of heat shock and significantly different from all time points thereafter. However, eventually a total increase in mitochondrial area of $52 \%$ after 90 min was noted. The number of mitochondria stayed relatively constant (fig. S2). The proportion of mitochondria enclosing EDC followed a similar trend to the nucleus, albeit with a less dramatic increase (fig. $4 \mathrm{~F})$.

Thus, during heat shock both nuclei and mitochondria vary in size throughout heat shock and also accumulate structures visible as EDC by electron microscopy. 
bioRxiv preprint doi: https://doi.org/10.1101/2021.01.25.428102; this version posted January 26, 2021. The copyright holder for this preprint (which was not certified by peer review) is the author/funder, who has granted bioRxiv a license to display the preprint in perpetuity. It is made available under aCC-BY-NC-ND 4.0 International license.

A

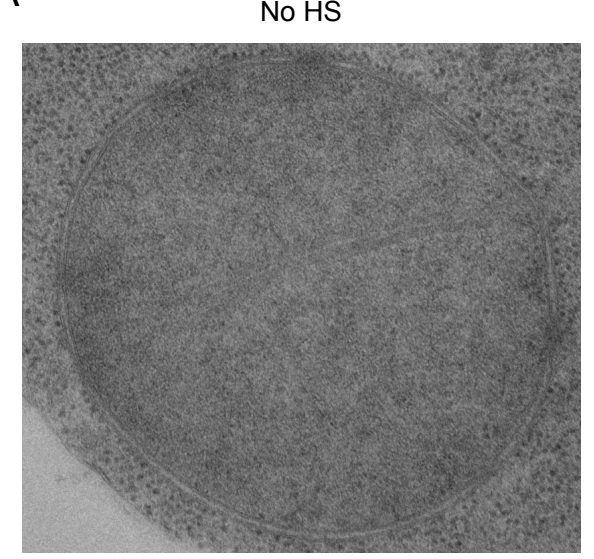

B $\quad n=224 \quad 163 \quad 243 \quad 204 \quad 234 \quad 225$

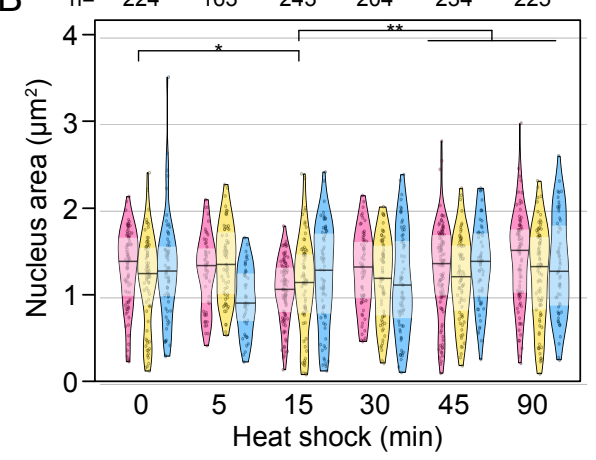

No HS

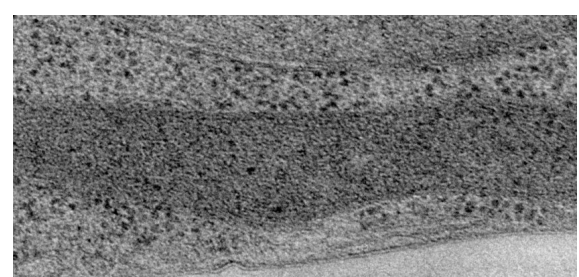

$\mathrm{E}$

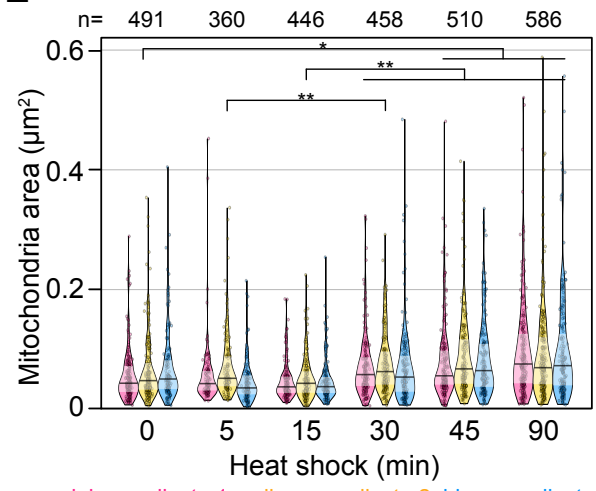

$30 \mathrm{~min} H \mathrm{~S}$

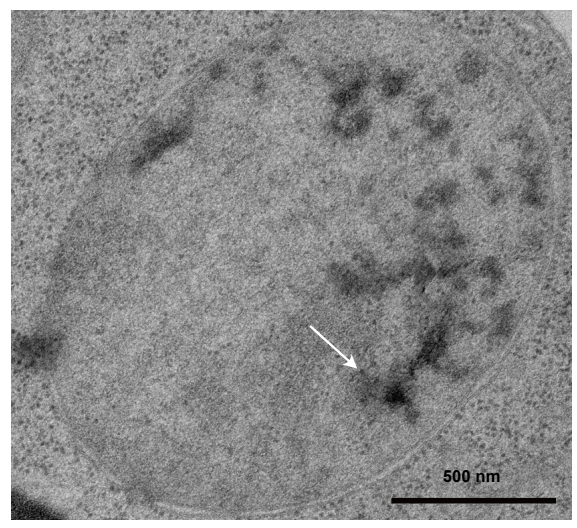

C

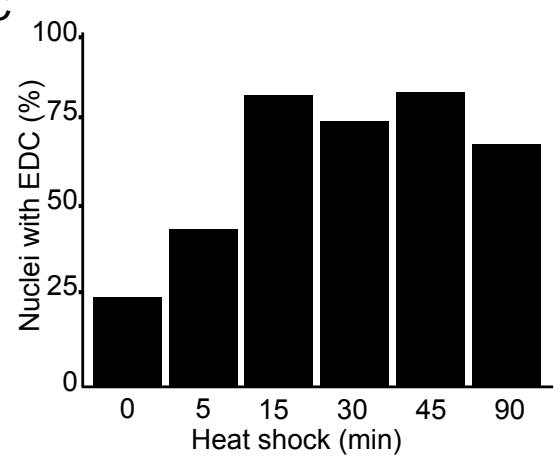

$30 \mathrm{~min} H \mathrm{H}$

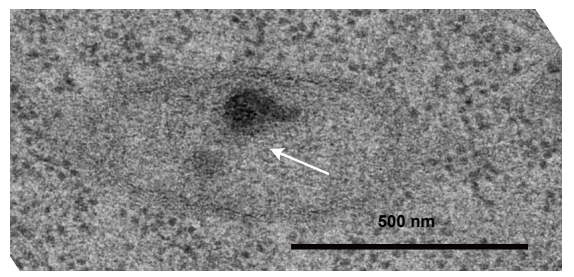

$\mathrm{F}$

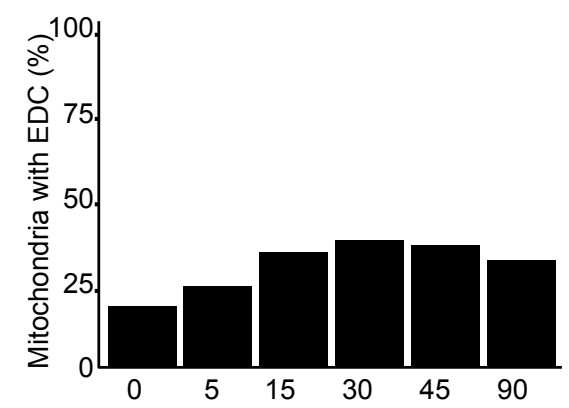

Figure 4. Nucleus and mitochondria change in size and morphology A) Nucleus morphology before and after 30 min heat shock, as electron dense content (EDC, arrow) appears. B) Nucleus area in electron micrographs of thin sections. The pink, yellow and blue shapes represent the three separate replicates. The width represents the number of measurements within a certain range of values, one point represents one measurement. Solid line is the median and inference bands are the interquartile ranges. C) Proportion of nuclei with EDC throughout heat shock. $n=1293$ nuclei. D) Mitochondria morphology before and after 30 min heat shock, as EDC (arrow) appears. E) Mitochondria area in electron micrographs of thin sections. On average, the mitochondria increase by $52 \%$ over the course of 90 minutes. F) Proportion of mitochondria with EDC throughout heat shock. $n=2851$ mitochondria. Significances: $\left({ }^{*}\right) p<0.05,\left({ }^{* *}\right) p \leq 0.01$. 
bioRxiv preprint doi: https://doi.org/10.1101/2021.01.25.428102; this version posted January 26, 2021. The copyright holder for this preprint (which was not certified by peer review) is the author/funder, who has granted bioRxiv a license to display the preprint in perpetuity. It is made available under aCC-BY-NC-ND 4.0 International license.

\section{MVBs and LDs increase in size during heat shock}

Two of the smallest cellular organelles, MVBs (fig. 5A) and LDs, displayed the greatest alteration in size over the heat shock time course, with both organelles' sizes increasing dramatically. The number of MVBs fluctuated during the time course, and after $15 \mathrm{~min}$ the cells contained 24\% more MVBs than before heat shock (fig. 5B). At the 15 min timepoint MVBs are also significantly different in size from the control (fig. 5C), and after 90 min they had increased in size by $73 \%$ (fig. 5C).

LDs (fig. 5D) also increased dramatically in number, and in cells subjected to $90 \mathrm{~min}$ of heat shock they were found 2.4 times as frequently as in the control group (fig. 5E). The first significant difference in size was observed after $30 \mathrm{~min}$, and by $90 \mathrm{~min}$ they had increased in size by $85 \%$ compared to their equivalent in untreated cells (fig. 5F). In brief, temperature stress leads to a general increase in the size and number of these small organelles.

A

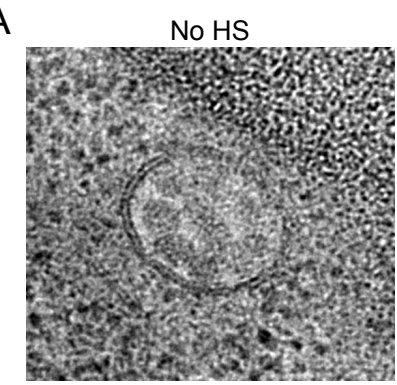

D

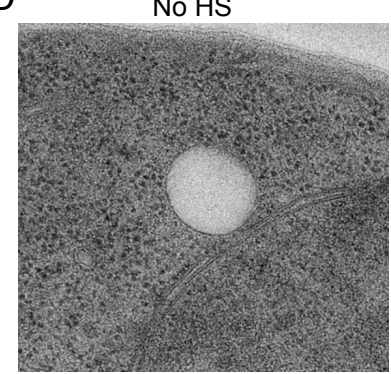

G

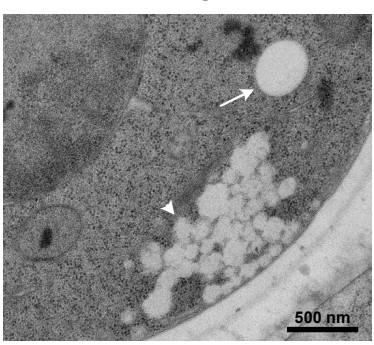

$30 \mathrm{~min} \mathrm{HS}$

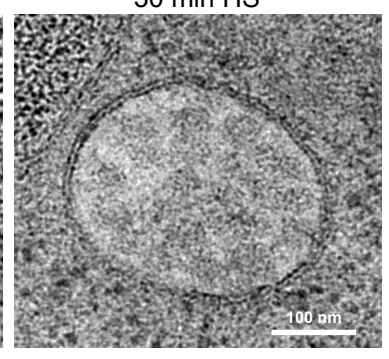

$30 \mathrm{~min} H \mathrm{HS}$

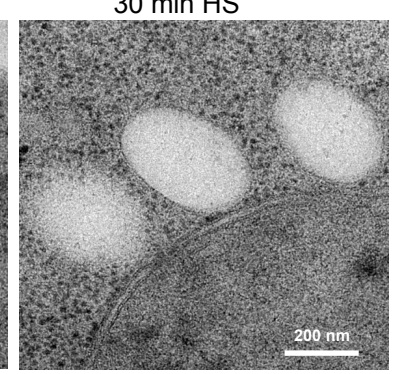

$\mathrm{H}$

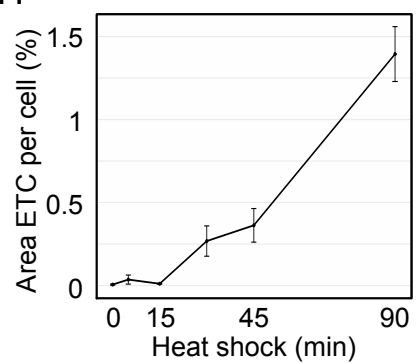

E
C
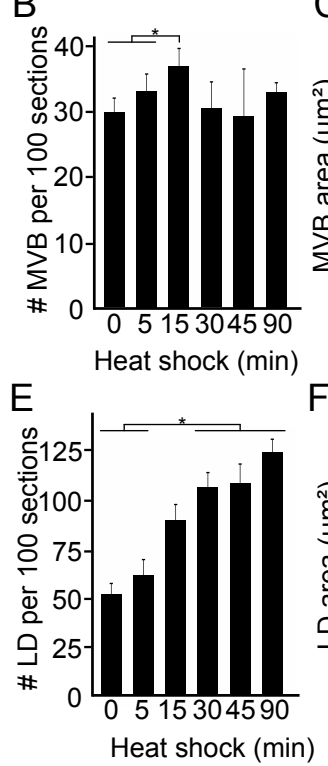

$\mathrm{F}$
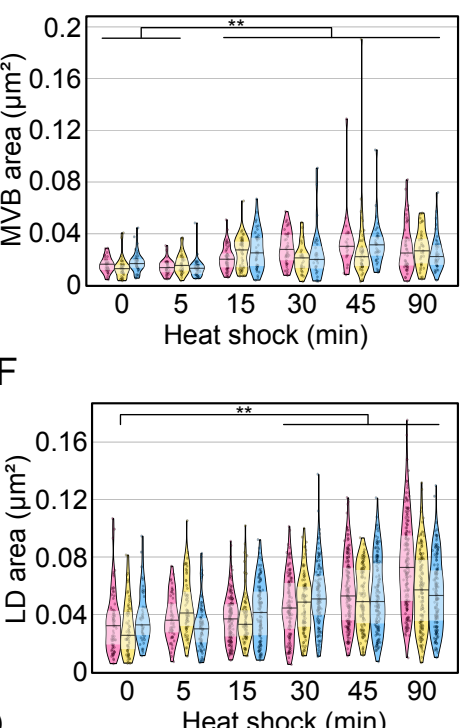

I

No HS

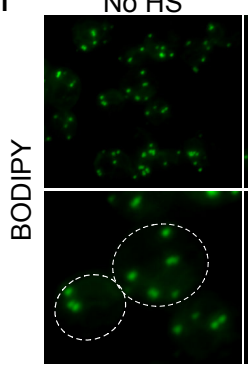

$45 \min \mathrm{HS}$

$90 \mathrm{~min} H \mathrm{HS}$

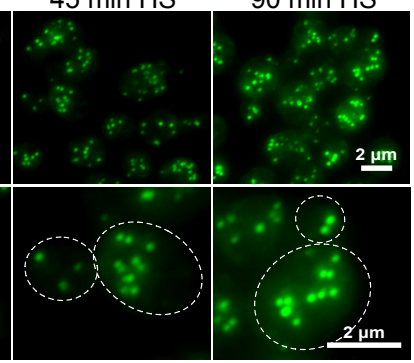

Figure 5. MVBs and LDs increase in size and a new phenotype appears A) MVB morphology before and after 30 min of heat shock. B) Number of MVBs, averaged over three sets with error bars corresponding to standard error of the mean. C) Area of MVBs, increased by $73 \%$ on average. The pink, yellow and blue shapes represent the three separate experiments. The width represents the number of measurements within a certain range of values, one point represents one measurement. Solid line is the median and inference bands are the interquartile ranges. D) LD morphology before and after 30 min of heat shock. E) Number of LDs, increased by factor 2.4, averaged over three sets with error bars corresponding to standard error of the mean. F) Area of LDs, increased by $85 \%$ on average. G) Electron translucent clusters (ETC) (arrowhead) next to an LD (arrow). H) Area of the cell section that was covered with electron translucent clusters over time in heat shock. I) Maximum projections of fluorescent images of cells stained with BODIPY for visualization of LDs. Significances: $\left({ }^{*}\right) p<0.05,\left({ }^{* *}\right) p \leq 0.01$. 


\section{Electron translucent clusters appear quickly after heat shock initiation and increase throughout}

Previously undescribed grape-like clusters of non-membrane enclosed electron translucent material appeared in heat shock (arrow head; fig. 5G). We named them electron translucent clusters (ETC) and could clearly distinguish them from electron translucent LDs (arrow; fig. $5 \mathrm{G}$ ), which are larger, clearly delimited from the cytoplasm and never appeared in such large clusters. Also, whilst LDs were most often observed close to the nucleus (fig. 5D and S3), ETC were often found in close proximity to the plasma membrane (fig. 5G and S3). The proportion of the cell area occupied by ETC steadily increased during the heat shock time course (fig. $5 \mathrm{H}$ ). After 90 min at $38^{\circ} \mathrm{C}$, an average of $1.4 \%$ of the cell's cross-sectional area was occupied by ETC, compared to barely having been present before heat shock (when $0.006 \%$ of the area was occupied by ETC, $\mathrm{n}=361$ cells).

To investigate whether the content of ETC and LDs was similar, we stained neutral lipids prominent in LDs (Murphy, 2001) using BODIPY, and compared fluorescence in untreated and heat shocked cells (fig. 5I). The fluorescence increased in a manner that corresponds well with the larger and more common LDs, but was not located near the plasma membrane where the ETC were found in electron micrographs, indicating that the composition of ETC differs to that of LDs. Therefore, throughout the heat shock time course, ETC of an unknown substance increasingly aggregate within the cell near the plasma membrane. 
A

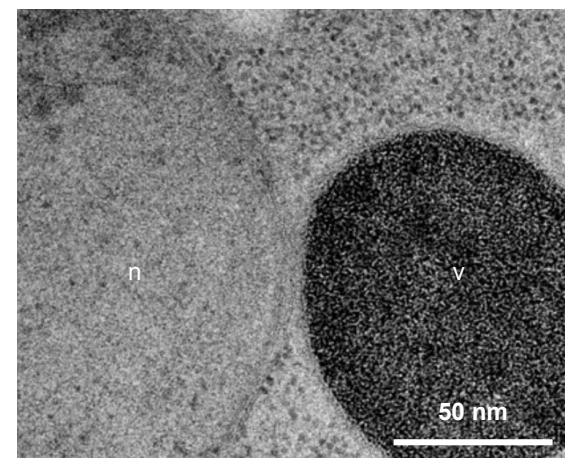

D

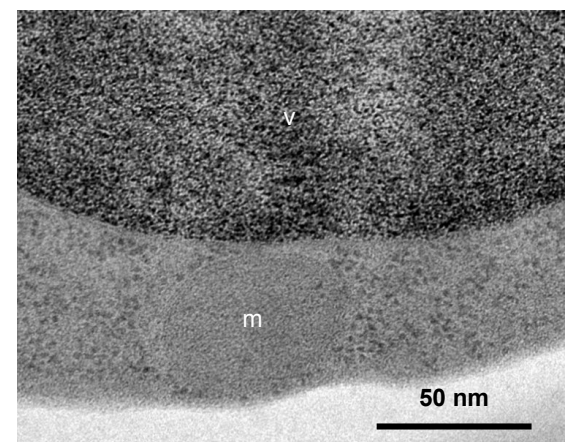

B

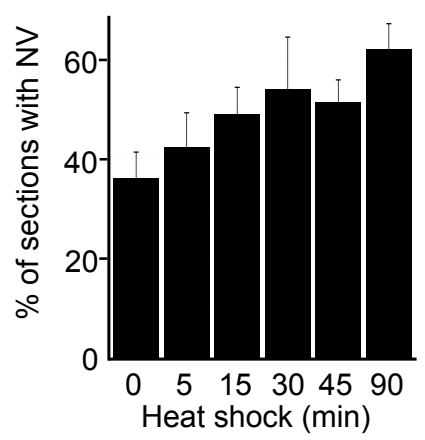

$E$

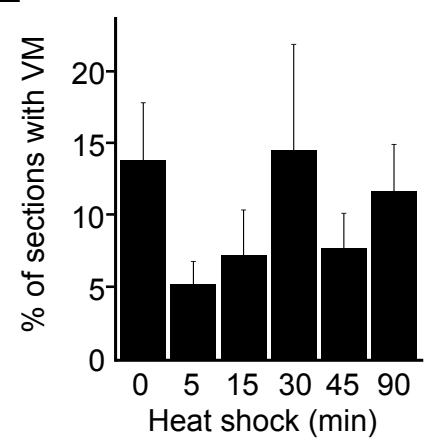

C

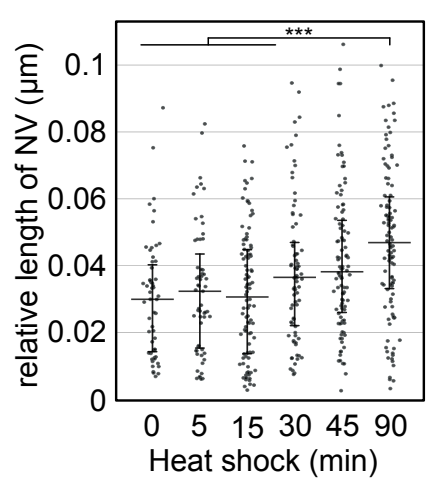

$\mathrm{F}$

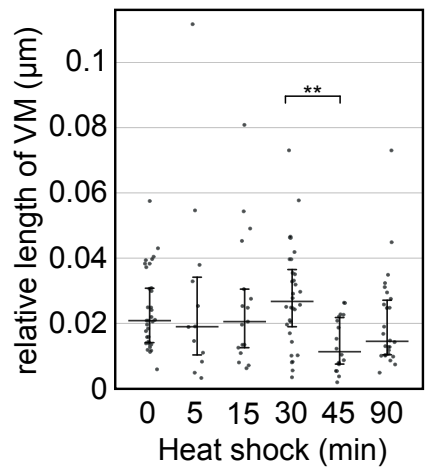

Figure 6. Membrane contact sites are influenced by heat shock $A$ ) Contact site between nucleus and vacuole (NV) B) Percentage of sections containing both nucleus and at least one vacuole with a contact site between the two. C) Length of contact site in relation to circumference of nucleus and vacuole. Black line is the median and error bars the interquartile range. D) Contact site between vacuole and mitochondrion (VM). E) Percentage of sections containing minimum one vacuole and minimum one mitochondrion with a contact site between the two. F) Length of contact site in relation to circumference of vacuole and mitochondria. Black line is the median and error bars the interquartile range. Significances: $\left({ }^{* *}\right) p \leq 0.01,\left({ }^{* * *}\right) \leq 0.001$.

\section{Physical interaction between vacuole and nucleus increases during heat shock}

Not only are organelles of the cell influenced by heat shock as individual components, but also their interactions with each other are affected. Organelles can communicate by forming areas of direct physical contact, called membrane contact sites (MCSs) enabling the exchange of ions, lipids, and signals between the organelles (Gottschling and Nyström, 2017). Although some MCSs are more intensively studied (Pan et al., 2000; Kornmann et al., 2009; Hönscher et al., 2014), MCSs have been identified between almost every cellular organelle (e.g. (Liu et $a l ., 2017)$ ). The high-resolution information provided by electron microscopy was used to quantify MCSs between nucleus and vacuole and between vacuole and mitochondria throughout the heat shock time course. An MCS was defined as membranes from two organelles in proximity to each other and not separated by any cytosolic ribosomes and its relative length was calculated in relation to the circumference of the adjoining organelles.

Contact sites between the nucleus and vacuoles (NV, fig. 6A), were not significantly more frequent (fig. 6B) but had increased in length by a total of $57 \%$ after 90 min of heat shock $(\mathrm{n}=$ 1033 sections, fig. 6C). The number of contact sites between vacuole and mitochondria (VM, fig. 6D) fluctuated strongly, both between time points and sets (fig. 6E). Despite a significant decrease in relative length between 30 and $45 \mathrm{~min}$, when vacuoles are at their largest, the size of VM contact sites did not significantly change (fig. 6F and fig. S4). When multiplying the 
proportion of sections that contain a contact site with the average absolute length, the surface area for potential interaction between the two organelles can be estimated and shows the same trend as the change in relative length (fig. S4).

In conclusion, we find that 90-min heat shock appears to specifically increase inter-organellar contact between nuclei and vacuoles but seems to have no to little observable effect on the physical interaction between vacuoles and mitochondria.

A

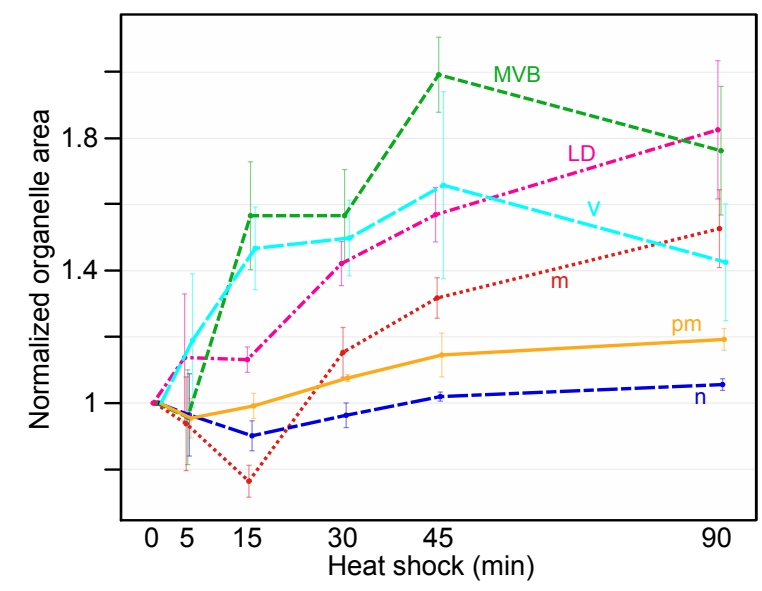

B

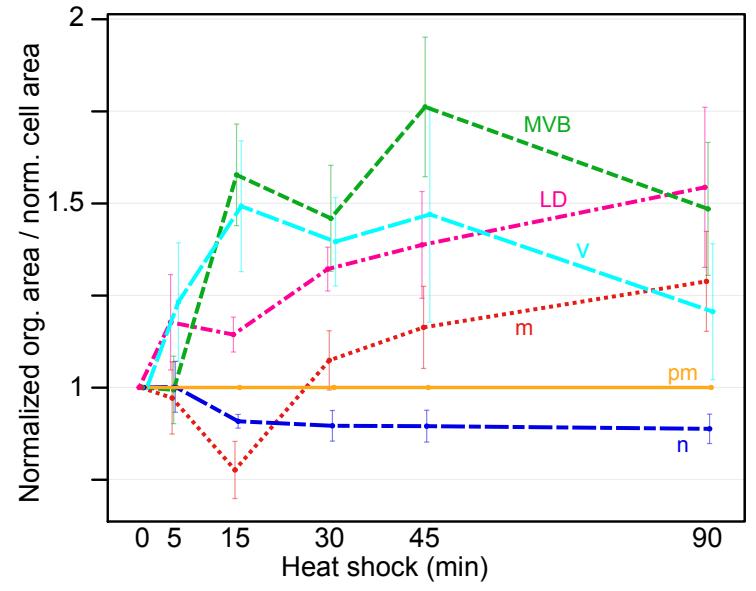

C

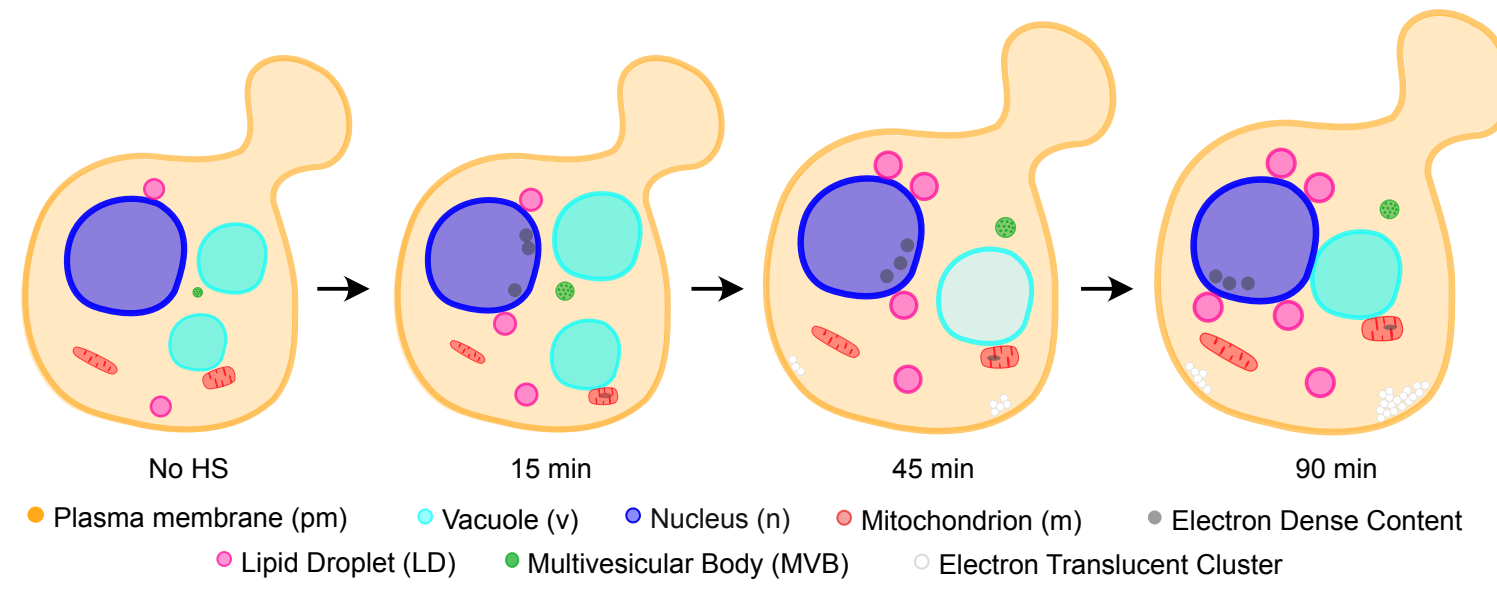

Figure 7. Model of structural changes occurring during mild heat shock A) Change in organelle area over heat shock with starting size normalized to 1 . Points represent the triplicate mean and error bars the standard error of the mean. B) Change in organelle area in relation to cell area at the respective time point with starting sizes normalized to 1 . C) Cartoon model of the changes in the whole cell over the course of 90 min.

\section{Discussion}

Our large-scale electron microscopy approach allows us to both analyse and quantify cellular changes during heat shock in a broad perspective and at high resolution. This showed that mild heat shock affects the size and form of every organelle we studied (fig. 7A), some more severely than others, and some with no previously known roles during heat shock, such as the MVB. It also allowed us to describe a completely new cellular structure - ETC.

\section{A map of large architectural changes to the cell during heat shock reveals dynamic changes in organellar size}


One could get the impression that the cell and its organelles respond to heat stress with a general size increase. This could be an effort of the cell to prevent macromolecular crowding, which influences diffusion within the cell as well as protein folding and aggregation (Ellis, 2001). To observe other intracellular interactions, organelle sizes were normalised and plotted in relation to the normalised cell area (fig. 7B), and their respective adaptations became clearer. The organelles' change in size could be matched up in pairs: cell-nucleus, mitochondria-LD and vacuole-MVB. After the $15 \mathrm{~min}$ timepoint both the cell and the nucleus have the same rate of increase in size. Vacuoles and MVBs both rapidly increase in size within the first $15 \mathrm{~min}$ and show similar rates of change in size throughout the rest of the time course. Mitochondria and LDs also have similar rates of increase in size starting the 15 min timepoint, revealing dynamic interaction between the two organelles. Indeed, LDs have previously been observed to serve as energy source for mitochondria during nutrient stress (Rambold, Cohen and LippincottSchwartz, 2015). In summary, this approach revealed a rapid, complex, and organelle-specific structural response to heat shock (fig. 7C).

\section{ETC are triggered by heat stress but are unlike LDs in their composition}

To our knowledge there are no previous descriptions of ETC in literature although similar structures are clearly visible in previously published electron micrographs of ts mutants at restrictive temperature (Novick, Field and Schekman, 1980; Poon et al., 1999; Marini et al., 2020). Here, we can only speculate as to their nature and function: the ETC's electron translucency is similar to that of LDs, indicating that they potentially are lipid deposits. However, the difference in morphology and the lack of BODIPY staining at the cell periphery speaks against the ETC being composed of the same neutral lipids that are found in LDs (Hsieh et al., 2012). Further, the majority of LDs are found in proximity to the nucleus, both in untreated cells and after 90 min heat shock (fig. S3). By contrast, other membrane-less structures that are known to accumulate during stress, such as p-bodies and stress granules, would be visible in electron micrographs as electron-dense structures as they contain mRNA which is stained dark by most electron microscopy preparation protocols (Cougot et al., 2012).

As opposed to other cellular components, throughout the heat shock time course ETC continued to steeply increase, accumulating near the plasma membrane. A possible explanation for this localisation could be related to the membrane's fluidity, which is known to increase under stress, especially heat-stress, in various organisms (Dynlacht and Fox, 1992; Lloyd et al., 1993; Mejía, Gómez-Eichelmann and Fernández, 1995; Török et al., 2014), and has been suggested to initiate the heat shock protein response (Balogh et al., 2005). A more fluid membrane, which has been observed to correlate with higher permeability (Wilkes et al., 1989), could allow material, such as extracellular fluid or components of the cell wall, to be released into the cytoplasm and observed as ETC in electron micrographs. Furthermore, unsaturated lipids may be deposited nearby to regulate membrane rigidity in higher temperatures.

Alternatively, it has been shown that the sugar trehalose accumulates in cells as a cytoprotectant during stress (Hughes and Gottschling, 2012) and the majority of carbohydrates, just like neutral lipids, are not fixed and stained by our preparation protocol, resulting in 
electron translucency. It is thus also possible that the ETC could be an accumulation of these carbohydrates.

\section{MVBs are involved in the cell's heat shock response}

MVBs are involved in the transport of membranous and cytoplasmic content but have no documented roles in the heat shock response to date. Although the number of MVBs remains constant throughout heat shock, their size increases significantly. This could mean that although their synthesis is not affected, the activity of existing MVBs is nevertheless upregulated. Because intraluminal vesicles formed from the MVB membrane do not only internalize membrane and membrane proteins, but also cytoplasmic content, they offer a proteasome-independent degradation of both membrane- and cytosolic proteins. Thus, their large increase in size throughout heat shock could indicate a need to support the cell's degradation and sorting machinery as MVBs transport ubiquitinated cargo (Piper and Katzmann, 2010). Interestingly, the increase in size of MVBs and of vacuoles follows a similar path (fig. 2E and 2F), supporting their potential influence on each other's activity.

\section{Vacuolar pH is affected by heat stress}

Besides an increase in size by almost half their original size, one of the most immediately noticeable changes are the difference in the morphology of the vacuoles. Due to the nature of the preparation protocol, all sets show fluctuations in the electron density of vacuoles, however set 3 is an outlier in its overall high numbers of electron-dense vacuoles. Our results strongly suggest that the different vacuolar electron densities reflect its internal $\mathrm{pH}$ and that the uranyl acetate stain can act as a potential $\mathrm{pH}$ probe in electron micrographs.

We see that heat stress affects the vacuolar $\mathrm{pH}$ in a similar manner that ageing does. In electron micrographs of dividing cells, the daughter had either higher or equal vacuolar electron density when compared to its mother. This is in line with observations that the $\mathrm{pH}$ of the vacuole is increased in the mother already after one division (Hughes and Gottschling, 2012). It may seem that deacidification of vacuolar $\mathrm{pH}$ during heat stress stems from an export of protons to the cytoplasm to cause the acidification necessary for the induction of HSF1, the main regulator gene of the heat shock response. However, it has been suggested that cells instead depend on the import of extracellular protons for acidification (Triandafillou et al., 2019). Observations of vacuolar invaginations, indentation and cytoplasmic vesicles (fig. S1 and (Ishii et al., 2018)) may indicate an indirect support of cytoplasmic acidification by increasing the proportion of imported protons relative to cytoplasmic content. The cause and mechanism for vacuolar deacidification remain unclear but the resulting impairment in function (Hughes and Gottschling, 2012) offers a potential explanation for the increase in the size of MVBs due to a block of trafficking to the vacuole.

\section{MCSs' response is specific and not directly proportional to organelle size}

It appears that the nuclear-vacuolar interaction is of particular importance for the heat shock response since the increase in size of contact sites between the nucleus and vacuoles during heat shock is much higher than would be accounted for by only the enlargement of the corresponding organelles. NV junctions have been shown to be sites for piecemeal 
microautophagy of the nucleus (Roberts et al., 2003) and localisations involved in lipid metabolism (Kohlwein et al., 2001; Levine and Munro, 2001).

Similarly, despite an increase in size of both vacuoles and mitochondria, contact sites between the organelles do not increase in size and number, as may be expected. Since vacuoles and mitochondria are closely linked and can form MCS, and vacuolar deacidification contributes to mitochondrial deterioration (Hughes and Gottschling, 2012), it is possible that keeping the number and size of contact sites constant prevents excessive damage to the cell during heat stress. Overall, this shows that there is a specificity in the regulation of the heat shock-induced response of organelle contact sites, the investigation of which has the potential to reveal much about cellular interconnectivity and metabolism under temperature stress. Due to the large size of vacuoles in comparison to the observed microscopy sections, contact sites with vacuoles may be underrepresented in quantification.

\section{A holistic approach relevant across multiple fields of research}

It is valuable to track global cellular changes occurring during heat shock to better understand how the stress response is coordinated. It is also important to be aware of these global changes when for example working with ts mutants where phenotypes attributed to the altered ts allele may instead be a direct or indirect effect of the heat shock itself.

Overall, this study has revealed the ways the cell is influenced by heat shock on a morphological level. Changes in structure, number and size of organelles is related to the molecular activity behind those processes and their careful and balanced interplay. This quantification of organelle changes highlights the importance of a holistic approach to answering research questions and creates a map and reference for those interested in reaction and adaptation to stress by eukaryotic cells.

\section{Materials and Methods}

\section{Yeast strains}

Yeast strains used in this study are derivatives of BY4741, here referred to as wt. Deletion strains have the gene of interest replaced by the KanMX cassette (EUROSCARF). HSP104GFP and VPH1-GFP are from the GFP-tagged collection (Huh et al., 2003). Strains are listed in Table 1.

\section{Growth conditions}

Cells were cultured at $30^{\circ} \mathrm{C}$ in rich YPD medium to mid-exponential phase. For heat shock, cell cultures were shifted to $38^{\circ} \mathrm{C}$ for indicated times before further analysis. The 0 min time point refers to the cultures at $30^{\circ} \mathrm{C}$, immediately before being exposed to heat shock.

\section{Fluorescence Microscopy}

For vacuolar $\mathrm{pH}$ analysis, $1 \mathrm{OD}_{600}$ of logarithmically growing cells were washed once in YPD +100 mM HEPES pH 7.6 and stained with $50 \mu \mathrm{M}$ BCECF-AM (ThermoFisher, Waltham MA, 
USA) dissolved in the same buffer at $30^{\circ} \mathrm{C}$ for $30 \mathrm{~min}$. Cells were washed twice in pre-warmed $100 \mathrm{mM}$ HEPES $\mathrm{pH} 7.6+2 \%$ glucose, resuspended in pre-warmed YPD and allowed to grow at either $30^{\circ} \mathrm{C}$ or $38^{\circ} \mathrm{C}$ for $45 \mathrm{~min}$. Cells were washed in pre-warmed $100 \mathrm{mM}$ HEPES pH 7.6 $+2 \%$ glucose then immediately imaged.

For visualisation of lipid droplets, approximately $1 \mathrm{OD}_{600}$ of wild type cells were harvested by centrifugation, resuspended in $1 \mathrm{ml} \mathrm{PBS}$, and incubated with $1 \mu \mathrm{g} / \mathrm{ml}$ BODIPY 493/503 (ThermoFisher, Waltham MA, USA) diluted in DMSO for $15 \mathrm{~min}$. Cells were washed once in PBS before imaged.

Hsp104-GFP and Vph1-GFP expressing cells were grown logarithmically, collected by centrifugation, and imaged directly.

Imaging of live yeast cells was performed with a Zeiss Axio Observer Z1 inverted fluorescent microscope equipped with an AxioCam MRm camera (Zeiss, Oberkochen, Germany). Plan Apo 100x oil objective NA:1.4 and the filter set 38 HEeGFP was used.

\section{Electron Microscopy}

Yeast cultures were grown to an $\mathrm{OD}_{600}$ of 0.5 , control cells were kept at $30^{\circ} \mathrm{C}$ and treated cells were heat shocked at $38^{\circ} \mathrm{C}$. After removal of medium by filtering through a $0.22 \mu \mathrm{m}$ filter, the cells were scraped off the filter membrane with a toothpick, transferred to an aluminium carrier and high-pressure frozen in a Wohlwend Compact 3 (M. Wohlwend GmbH, Sennwald, Switzerland). Freeze substitution was performed in a Leica AFS2 (Leica Microsystems GmbH, Wetzlar, Germany) with an incubation in 2\% uranyl acetate in acetone (UA; SPI Supplies, West Chester PA, USA) for 1h, rinsing in acetone and embedding in Lowicryl HM20 resin (Polysciences, Warrington PA, USA) (Hawes et al., 2007). Polymerised resin blocks were sectioned to $70 \mathrm{~nm}$ thickness using a Reichert Ultracut S (Reichert, Vienna, Austria) and placed on Formvar-coated 200-mesh or slot copper grids. Grids were contrast-stained using a 2\% aqueous UA solution for 5 min and Reynold's lead citrate (Reynolds, 1963) 1 min. Samples were imaged at $120 \mathrm{kV}$ on a FEI Tecnai G2 Spirit with an FEI Ceta $16 \mathrm{M}$ camera (4k x 4k) (Thermo Fisher Scientific, Waltham MA, USA) and a pixel size of $1.1 \mathrm{~nm}$ for a magnification of 9300x.

\section{Image Analysis and Quantification}

Number of vacuoles per cell was determined in fluorescence microscopy images of Vph1-GFP cells by manual counting of $\geq 200$ cells per replicate and time point in Fiji (Schindelin et al., 2012). Vacuolar area was quantified for $\geq 200$ vacuoles per replicate and time point using the freehand area tool in Fiji on maximum projections of microscopy images of Vph1-GFP cells.

Electron micrographs were quantified using the program IMOD (Kremer, Mastronarde and McIntosh, 1996), by drawing outlines of the structures of interest. Structures such as vacuoles, mitochondria and nuclei were also classified according to morphology. In total, 2143 micrographs were analysed for the time course, corresponding to a full-cell volume of 37 cells, assuming a cell diameter of $4 \mu \mathrm{m}$. The length of contact sites was put in relation to the circumference of the respective organelles in contact. 
Vacuolar acidity was quantified using Fiji by measuring BCECF-AM mean fluorescence intensity of $\geq 30$ vacuoles per condition from three independent experiments respectively.

\section{Statistical analysis}

After the measurements were obtained from the models, replicates 1, 2, and 3 were treated as one batch. Normality for each timepoint and organelle was checked using a Shapiro-Wilk-test. Where possible (cell and MVB area), measurement distribution was normalised using a BoxCox transform (Manolson et al., 1992) $(\mathrm{l}=0.63$ and $\mathrm{l}=0.4)$, equal variances confirmed with Bartlett's test and one-way ANOVA performed (cell area). In the case of unequal variances, pairwise t-tests using non-pooled standard deviation were performed (MVB area). Pairwise group comparisons were performed using the R package emmmeans (Lenth et al., 2020). Nonnormally distributed data that could not be normalised was analysed with Dunn's test. All pvalues were adjusted according to Holm (Holm, 1979).

Where significant differences between replicates 1, 2, and 3 were found, sets were analysed individually and the most conservative p-values shown, these instances are mitochondrial and LD area. Scatter plots show non-transformed data to allow more intuitive interpretation of area values.

\section{Acknowledgements}

The authors would like to thank Mattia Donà, Claes Andreasson, Sabrina Büttner, and Martin Ott for insightful and helpful scientific discussions.

\section{Competing Interests}

The authors declare no competing interests.

\section{Funding}

This work was supported by grants from the Knut and Alice Wallenberg Foundation (KAW 2017.0091).

\section{Data Availability}

No publicly available data sets were generated. 


\section{References}

Balogh, G. et al. (2005) "The hyperfluidization of mammalian cell membranes acts as a signal to initiate the heat shock protein response," FEBS Journal, 272(23), pp. 6077-6086. doi: 10.1111/j.1742-4658.2005.04999.x.

Chung, C. G., Lee, H. and Lee, S. B. (2018) "Mechanisms of protein toxicity in neurodegenerative diseases," Cellular and Molecular Life Sciences, 75(17), pp. 3159-3180. doi: 10.1007/s00018-018-2854-4.

Cougot, N. et al. (2012) "The Dual Organization of P-bodies Revealed by Immunoelectron Microscopy and Electron Tomography," Journal of Molecular Biology, 420(1-2), pp. 17-28. doi: 10.1016/j.jmb.2012.03.027.

Dynlacht, J. R. and Fox, M. H. (1992) "Effects of hyperthermia and membrane-active compounds or low ph on the membrane fluidity of chinese hamster ovary cells," International Journal of Hyperthermia, 8(3), pp. 351-362. doi: $10.3109 / 02656739209021790$.

Ellis, R. J. (2001) "Macromolecular crowding: an important but neglected aspect of the intracellular environment," Current Opinion in Structural Biology, 11(1), pp. 114-119. doi: 10.1016/S0959-440X(00)00172-X.

Escusa-Toret, S., Vonk, W. I. M. and Frydman, J. (2013) "Spatial sequestration of misfolded proteins by a dynamic chaperone pathway enhances cellular fitness during stress," Nature Cell Biology, 15(10), pp. 1231-1243. doi: 10.1038/ncb2838.

Gao, Q. et al. (2017) "Pet10p is a yeast perilipin that stabilizes lipid droplets and promotes their assembly," Journal of Cell Biology, 216(10), pp. 3199-3217. doi: $10.1083 /$ jcb.201610013.

Gottschling, D. and Nyström, T. (2017) "The up- and down-sides of organelle interconnectivity,” Cell, 169(1), pp. 24-34. doi: 10.1016/j.cell.2017.02.030.

Hawes, P. et al. (2007) "Rapid freeze-substitution preserves membranes in high-pressure frozen tissue culture cells," Journal of Microscopy, 226(2), pp. 182-189. doi: 10.1111/j.1365-2818.2007.01767.x.

Hecht, K. A., O'Donnell, A. F. and Brodsky, J. L. (2014) "The proteolytic landscape of the yeast vacuole," Cellular Logistics, 4(1), p. e28023. doi: 10.4161/cl.28023.

Holm, S. (1979) “A simple sequentially rejective multiple test procedure," Scandinavian journal of statistics.

Hönscher, C. et al. (2014) "Cellular Metabolism Regulates Contact Sites between Vacuoles and Mitochondria," Developmental Cell, 30(1), pp. 86-94. doi:

10.1016/j.devcel.2014.06.006.

Hsieh, K. et al. (2012) "Perilipin family members preferentially sequester to either triacylglycerol-specific or cholesteryl-esterspecific intracellular lipid storage droplets," Journal of Cell Science, 125(17), pp. 4067-4076. doi: 10.1242/jcs.104943. 
Hughes, A. L. and Gottschling, D. E. (2012) "An early age increase in vacuolar pH limits mitochondrial function and lifespan in yeast," Nature, 492(7428), pp. 261-265. doi: 10.1038/nature11654.

Huh et al. (2003) "Global analysis of protein localization in budding yeast.," Nature, 425(6959), pp. 686-691.

Ishii, A. et al. (2018) "Accelerated invagination of vacuoles as a stress response in chronically heat-stressed yeasts," Scientific Reports, 8(1), pp. 1-11. doi: 10.1038/s41598018-20781-8.

Kaliszewska, M. et al. (2015) "Yeast model analysis of novel polymerase gamma variants found in patients with autosomal recessive mitochondrial disease," Human Genetics, 134(9), pp. 951-966. doi: 10.1007/s00439-015-1578-x.

Kohlwein, S. D. et al. (2001) "Tsc13p Is Required for Fatty Acid Elongation and Localizes to a Novel Structure at the Nuclear-Vacuolar Interface in Saccharomyces cerevisiae," Molecular and Cellular Biology, 21(1), pp. 109-125. doi: 10.1128/MCB.21.1.109.

Kornmann, B. et al. (2009) "An ER-Mitochondria Tethering Complex Revealed by a Synthetic Biology Screen,” Science, 325(5939), pp. 477-481. doi: 10.1126/science.1175088.

Kremer, J. R., Mastronarde, D. N. and McIntosh, J. R. (1996) "Computer visualization of three-dimensional image data using IMOD," Journal of Structural Biology, 116(1), pp. 7176. doi: 10.1006/jsbi.1996.0013.

Lenth, R. et al. (2020) “emmeans : Estimated Marginal Means, aka Least-Squares Means," $R$ package version 1.15-15. doi: 10.1080/00031305.1980.10483031.

Levine, T. P. and Munro, S. (2001) "Dual Targeting of Osh1p, a Yeast Homologue of Oxysterol-binding Protein, to both the Golgi and the Nucleus-Vacuole Junction," 12(June), pp. 1633-1644.

Lewandowska, A. et al. (2006) "Hsp78 chaperone functions in restoration of mitochondrial network following heat stress," Biochimica et Biophysica Acta-Molecular Cell Research, 1763(2), pp. 141-151. doi: 10.1016/j.bbamcr.2006.01.007.

Li, S. C. and Kane, P. M. (2009) "The yeast lysosome-like vacuole: Endpoint and crossroads," Biochimica et Biophysica Acta (BBA) - Molecular Cell Research, 1793(4), pp. 650-663. doi: 10.1016/j.bbamcr.2008.08.003.

Liu, L.-K. et al. (2017) "An inducible ER-Golgi tether facilitates ceramide transport to alleviate lipotoxicity," Journal of Cell Biology, 216(1), pp. 131-147. doi: 10.1083/jcb.201606059.

Lloyd, D. et al. (1993) "Effects of growth with ethanol on fermentation and membrane fluidity of Saccharomyces cerevisiae," Yeast, 9(8), pp. 825-833. doi: 10.1002/yea.320090803.

Manolson, M. F. et al. (1992) “The VPH1 gene encodes a 95-kDa integral membrane polypeptide required for in vivo assembly and activity of the yeast vacuolar H+-ATPase," Journal of Biological Chemistry, 267(20), pp. 14294-14303. 
Marini, G. et al. (2020) "Reorganization of budding yeast cytoplasm upon energy depletion," Molecular biology of the cell, 31(12), pp. 1232-1245. doi: 10.1091/mbc.E20-02-0125.

Meaden, P. G. et al. (1999) "Endocytosis and vacuolar morphology in Saccharomyces cerevisiae are altered in response to ethanol stress or heat shock," Yeast, 15(12), pp. 12111222. doi: 10.1002/(SICI)1097-0061(19990915)15:12<1211::AID-YEA448>3.0.CO;2-H.

Mejía, R., Gómez-Eichelmann, M. C. and Fernández, M. S. (1995) "Membrane fluidity of Escherichia coli during heat-shock," BBA - Biomembranes, 1239(2), pp. 195-200. doi: 10.1016/0005-2736(95)00152-S.

Meyers, A. et al. (2016) "Lipid Droplets Form from Distinct Regions of the Cell in the Fission Yeast Schizosaccharomyces pombe.," Traffic, 17(6), pp. 657-69. doi: $10.1111 /$ tra. 12394.

Moor, H. (1987) "Theory and Practice of High Pressure Freezing," in Cryotechniques in Biological Electron Microscopy. Berlin, Heidelberg: Springer Berlin Heidelberg, pp. 175191. doi: 10.1007/978-3-642-72815-0_8.

Morimoto, R. I. (1993) "Cells in stress: Transcriptional activation of heat shock genes," Science, 259(5100), pp. 1409-1410. doi: 10.1126/science.8451637.

Morimoto, R. I. and Westerheide, S. D. (2010) "The heat shock response and the stress of misfolded proteins," in Handbook of Cell Signaling, 2/e. doi: 10.1016/B978-0-12-3741455.00268-0.

Mühlhofer, M. et al. (2019) "The Heat Shock Response in Yeast Maintains Protein Homeostasis by Chaperoning and Replenishing Proteins," Cell Reports, 29(13), pp. 45934607.e8. doi: 10.1016/j.celrep.2019.11.109.

Murphy, D. (2001) "The biogenesis and functions of lipid bodies in animals, plants and microorganisms," Progress in Lipid Research, 40(5), pp. 325-438. doi: 10.1016/S01637827(01)00013-3.

Novick, P., Field, C. and Schekman, R. (1980) "Identification of 23 complementation groups required for post-translational events in the yeast secretory pathway.," Cell, 21(1), pp. 20515. doi: 10.1016/0092-8674(80)90128-2.

Pan, X. et al. (2000) "Nucleus-Vacuole Junctions in Saccharomyces cerevisiae Are Formed Through the Direct Interaction of Vac8p with Nvj1p," Molecular Biology of the Cell. Edited by P. Walter, 11(7), pp. 2445-2457. doi: 10.1091/mbc.11.7.2445.

Perktold, A. et al. (2007) "Organelle association visualized by three-dimensional ultrastructural imaging of the yeast cell," FEMS Yeast Research, 7(4), pp. 629-638. doi: 10.1111/j.1567-1364.2007.00226.x.

Piper, R. C. and Katzmann, D. J. (2010) "Biogenesis and function of MVBs," Annual Review of Cell and Developmental Biology, 23, pp. 519-547. doi: 10.1146/annurev.cellbio.23.090506.123319.Biogenesis.

Plant, P. J. et al. (1999) Alternative Mechanisms of Vacuolar Acidification in H-ATPasedeficient Yeast* Downloaded from, THE JOURNAL OF BIOLOGICAL CHEMISTRY. Available at: http://www.jbc.org/. 
Poon, P. P. et al. (1999) "Retrograde transport from the yeast Golgi is mediated by two ARF GAP proteins with overlapping function," EMBO Journal, 18(3), pp. 555-564. doi: 10.1093/emboj/18.3.555.

Rambold, A. S., Cohen, S. and Lippincott-Schwartz, J. (2015) "Fatty acid trafficking in starved cells: Regulation by lipid droplet lipolysis, autophagy, and mitochondrial fusion dynamics," Developmental Cell, 32(6), pp. 678-692. doi: 10.1016/j.devcel.2015.01.029.

Reynolds, E. S. (1963) "The use of lead citrate at high $\mathrm{pH}$ as an electron-opaque stain in electron microscopy.," The Journal of cell biology, 17(1), pp. 208-212. doi: 10.1083/jcb.17.1.208.

Roberts, P. et al. (2003) "Piecemeal Microautophagy of Nucleus in Saccharomyces cerevisiae," Molecular Biology of the Cell, 14, pp. 129-141. doi: 10.1091/mbc.E02.

Schindelin, J. et al. (2012) "Fiji: An open-source platform for biological-image analysis," Nature Methods. doi: 10.1038/nmeth.2019.

Shi, Y., Mosser, D. D. and Morimoto, R. I. (1998) "Molecular chaperones as HSF1-specific transcriptional repressors," Genes and Development, 12(5), pp. 654-666. doi: 10.1101/gad.12.5.654.

Spokoini, R. et al. (2012) "Confinement to Organelle-Associated Inclusion Structures Mediates Asymmetric Inheritance of Aggregated Protein in Budding Yeast," Cell Reports, 2(4), pp. 738-747. doi: 10.1016/j.celrep.2012.08.024.

Takalo, M. et al. (2013) "Protein aggregation and degradation mechanisms in neurodegenerative diseases," American Journal of Neurodegenerative Diseases, 2(1), pp. 114.

Tenreiro, S. et al. (2013) "Harnessing the power of yeast to unravel the molecular basis of neurodegeneration," Journal of Neurochemistry, 127(4), pp. 438-452. doi: 10.1111/jnc. 12271 .

Török, Z. et al. (2014) "Plasma membranes as heat stress sensors: From lipid-controlled molecular switches to therapeutic applications," Biochimica et Biophysica Acta Biomembranes, 1838(6), pp. 1594-1618. doi: 10.1016/j.bbamem.2013.12.015.

Triandafillou, C. G. et al. (2019) "Transient Intracellular Acidification Regulates the Core Transcriptional Heat Shock Response.” doi: https://doi.org/10.1101/414706.

Verghese, J. et al. (2012a) "Biology of the Heat Shock Response and Protein Chaperones: Budding Yeast (Saccharomyces cerevisiae) as a Model System," Microbiology and Molecular Biology Reviews, 76(2), pp. 115-158. doi: 10.1128/mmbr.05018-11.

Verghese, J. et al. (2012b) "Biology of the Heat Shock Response and Protein Chaperones: Budding Yeast (Saccharomyces cerevisiae) as a Model System," Microbiology and Molecular Biology Reviews, 76(2), pp. 115-158. doi: 10.1128/mmbr.05018-11.

Wilkes, J. M. et al. (1989) "Proton permeability and lipid dynamics of gastric and duodenal apical membrane vesicles," American Journal of Physiology - Gastrointestinal and Liver Physiology, 256(3). doi: 10.1152/ajpgi.1989.256.3.g553. 
bioRxiv preprint doi: https://doi.org/10.1101/2021.01.25.428102; this version posted January $26,2021$. The copyright holder for this

preprint (which was not certified by peer review) is the author/funder, who has granted bioRxiv a license to display the preprint in perpetuity. It is made available under aCC-BY-NC-ND 4.0 International license.

Winderickx, J. et al. (2008) "Protein folding diseases and neurodegeneration: Lessons learned from yeast," Biochimica et Biophysica Acta - Molecular Cell Research, 1783(7), pp. 1381-1395. doi: 10.1016/j.bbamcr.2008.01.020. 
bioRxiv preprint doi: https://doi.org/10.1101/2021.01.25.428102; this version posted January 26, 2021. The copyright holder for this preprint (which was not certified by peer review) is the author/funder, who has granted bioRxiv a license to display the preprint in perpetuity. It is made available under aCC-BY-NC-ND 4.0 International license.

\section{Supplementary figures}
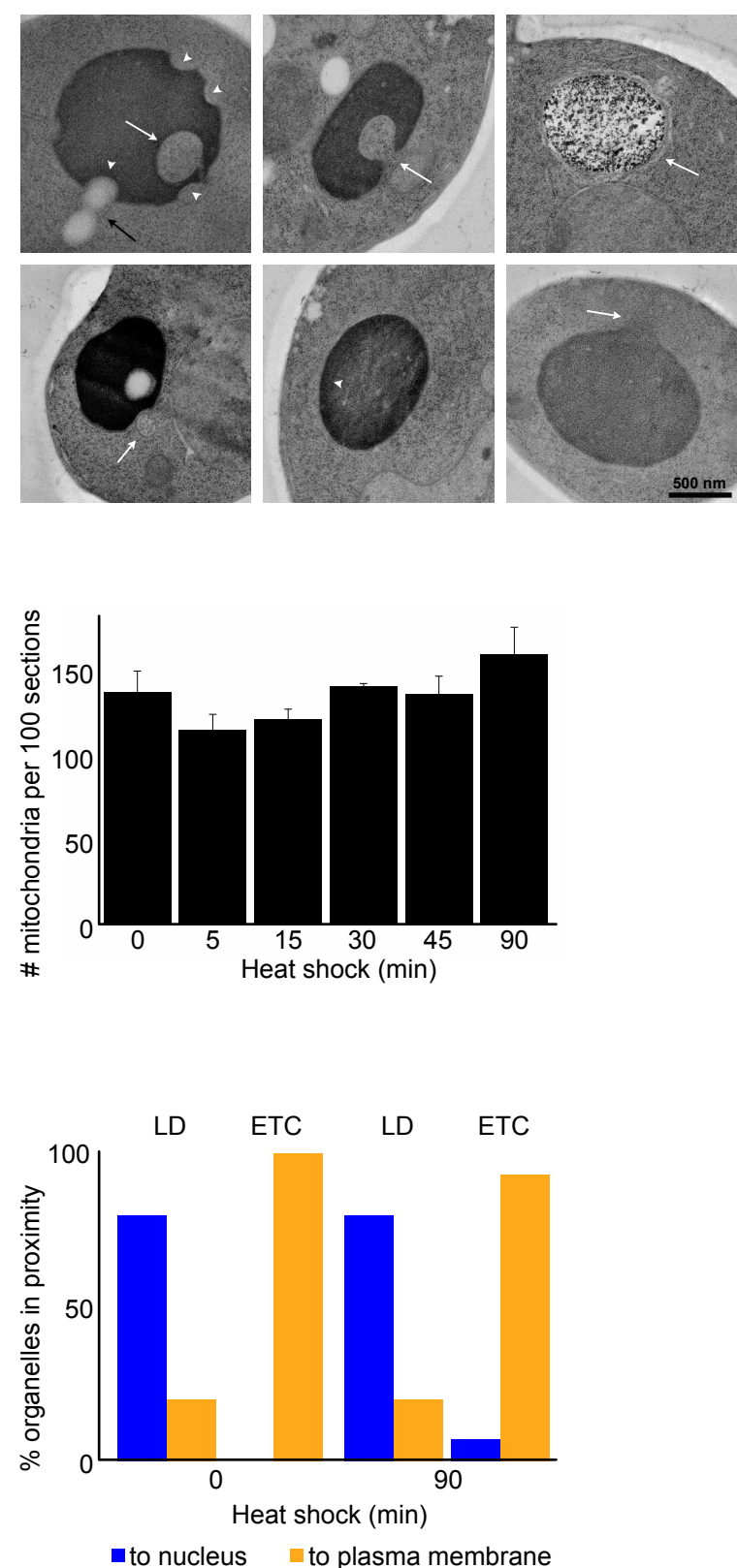

Figure S1. Gallery of vacuolar morphologies in heat shocked cells (Top) Left: indentations in the vacuolar membrane (arrowheads), LDs (black arrow) and cytoplasmic vesicle contained inside the vacuole (white arrow), Middle: Invagination into vacuole (arrow), Right: Dark precipitates deposited onto the vacuole (arrow). (Bottom) Left: an MVB (arrow) near an indentation of a vacuole, Middle: electron dense ring at the periphery of the vacuole (arrowhead), Right: vacuole seemingly "leaking" content into cytoplasm (arrow).

Figure S2. Number of mitochondria does not vary significantly throughout heat shock when observed with EM A) Number of mitochondria per 100 cell sections in cells subjected to indicated times of HS. $300+$ cells were analyzed per time point. Error bars are standard error of the mean.

Figure S3. LDs are closer to nucleus and ETC to the plasma membrane A) Proportion of lipid droplets (LD) and electron-translucent clusters (ETC) respectively closer to the nucleus or plasma membrane before heat shock and after 90 min heat shock. $n=50 \mathrm{LD}$ and $22 \mathrm{ETC}$ at $0 \mathrm{~min}$ and $\mathrm{n}=50 \mathrm{LD}$ and 57 ETC at 90 min heat shock. 
A

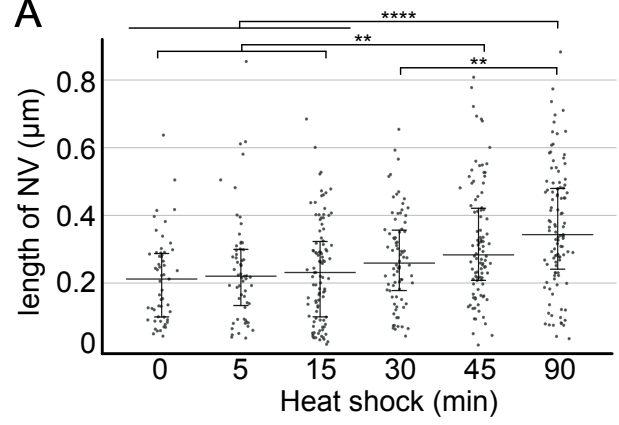

C

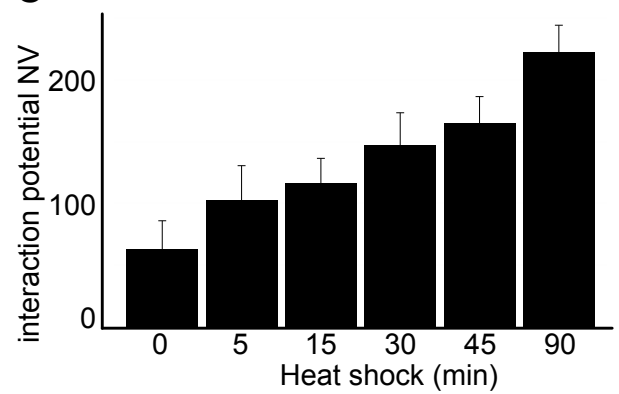

B

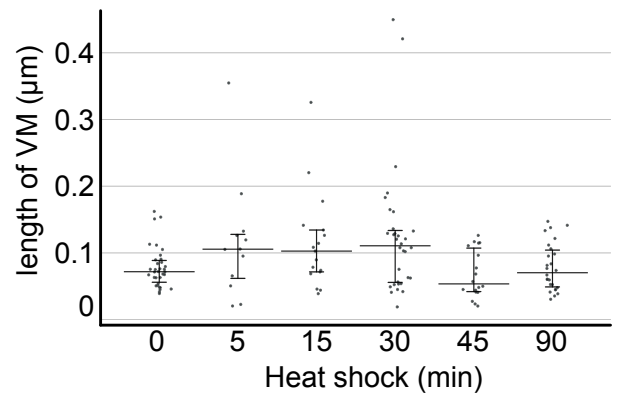

$\mathrm{D}$

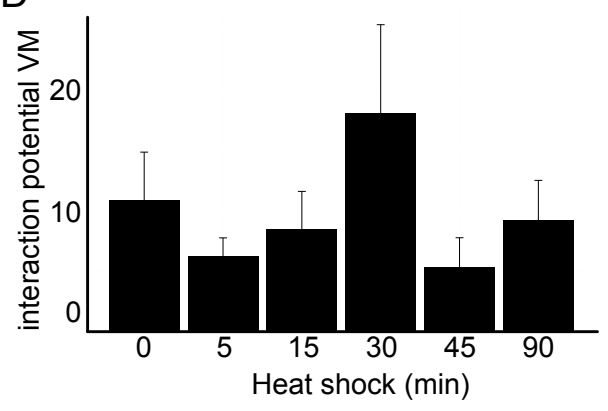

Figure S4. Membrane contact sites are influenced by heat shock A) Absolute length of contact site between nucleus and vacuole (NV). Black line is the median and error bars the interquartile range. Significances: $\left({ }^{* *}\right) p \leq 0.01,\left({ }^{* * * *}\right) \leq 0.0001$. B) Absolute length of contact site between vacuole and mitochondria (VM). Black line is the median and error bars the interquartile range. No significant differences found. C) Interaction potential (arbitrary units) between the nucleus and vacuole, corresponding to the average proportion of sections with contact sites multiplied by the average absolute length in $\mathrm{nm}$. D) Interaction potential (arbitrary units) between the vacuole and mitochondria, corresponding to the average proportion of sections with contact sites multiplied by the average absolute length in $\mathrm{nm}$. Error bars are standard errors of the mean. 